\title{
Effect of Patent Ductus Arteriosus on Water Accumulation and Protein Permeability in the Lungs of Mechanically Ventilated Premature Lambs
}

\author{
GAD ALPAN, FRANÇOISE MAURAY, and RONALD I. CLYMAN \\ Cardiovascular Research Institute and Department of Pediatrics, University of California, San Francisco, \\ California 94143
}

\begin{abstract}
To examine the effect of a patent ductus arteriosus on water accumulation and protein permeability in the premature, ventilated long, we studied 16 lambs at 121-127 d gestation (term = $145 \mathrm{~d}$ ). Water accumulation was assessed by the wet:dry wt ratio of the blood-free left lung. Protein permeability was assessed by the albumin content and by the recovery of ${ }^{125} \mathrm{I}$-albumin in the right lung lavage fluid $\mathbf{l} \mathrm{h}$ after intravenous injection. Using a model that allows mechanical control of ductus patency, we compared nine lambs with patent ductus (left-to-right shunts $42 \pm 18 \%$ of left ventricular output) with seven lambs with closed ductus. The animals were studied over $3 \mathrm{~h}$. In the open ductus lambs, $0.85 \pm 0.36$ and $1.76 \pm$ $1.87 \% / \mathrm{h}$ of the injected ${ }^{125}$ I-albumin was recovered in the lavage fluid and lung tissue, respectively. In the closed ductus lambs, the corresponding amounts were $0.71 \pm 0.21$ and $0.71 \pm 0.22 \% / h$; these differences were not statistically significant. Similarly, biood-free wet:dry ratios did not differ significantly between the two groups $(7.01 \pm 1.28$ open ductus versus $6.55 \pm 0.82$ closed ductus). We concluded that patency of the ductus arteriosus does not significantly affect water accumulation and net protein transudation into the airways of preterm lambs in the first hours of life. Therefore, some other feature of immaturity must be responsible for the large protein leaks previously observed by others. (Pediatr Res 26:570-575, 1989)
\end{abstract}

\section{Abbreviation}

PDA, patent ductus arteriosus

In premature infants who develop respiratory distress syndrome, a PDA increases the risk of respiratory failure. Low serum protein concentration and high alveolar surface tension in the lungs of these infants may increase the rate of fluid filtration into the alveolar spaces ( $1-3$ ), and the additional burden imposed by patency of the ductus arteriosus may aggravate these predisposing factors. Because PDA has been associated with increased pulmonary blood flow, pulmonary blood pressure, and

Received May 22, 1989; accepted July 26, 1989

Correspondence Ronald I. Clyman, M.D., 1403 HSE, Box 0544, University of California, San Francisco, CA 94143.

Supported by a Pulmonary Special Center of Research Grant HL 27356 from the United States Public Health Service. G.A. was supported by an American Heart Association, California Affiliate, fellowship with funds contributed by the San Mateo County chapter. left ventricular end-diastolic pressure $(4,5)$ its presence has been implicated as a cause of pulmonary edema in the premature infant with respiratory distress $(6,7)$. Based on these hypotheses, and on the observation that $90 \%$ of preterm infants with respiratory distress have a PDA in the furst $24 \mathrm{~h}(8)$, several clinical trials have been performed to study the effects of early closure of the PDA on respiratory disease. However, little information is available to demonstrate the mechanism by which the ductus adversely affects respiratory function.

Recent work has shown that mechanically ventilated premature lambs and goats with respiratory distress exhibit an increased permeability to serum proteins $(9-11)$ that is inversely related to gestational age $(11,12)$. Although this increased permeability was attributed to immaturity, in one of these studies the animals also had PDA with left-to-right shunts of 14 to $30 \%$ of left ventricular output (9). In the other studies, ductal patency was not assessed. Thus, whether the protein leaks were due to mechanical ventilation of immature lungs or whether they were secondary to the presence of a PDA could not be answered by these studies. Decreased protein leaks with advancing gestational age (12) could be attributed to the increased rate of spontaneous closure of the ductus arteriosus with increasing gestation (1315).

In our study we set out to determine whether the increased rate of water accumulation and net protein flux into the lungs of mechanically ventilated premature lambs could be attributed to patency of the ductus arteriosus. We did this by comparing several indices of albumin flux and water accumulation in the lungs of two groups of premature lambs, one with open ductus and one with closed ductus, over a period of $3 \mathrm{~h}$ after delivery.

\section{MATERIALS AND METHODS}

SURGICAL PREPARATION. Surgery was performed on time-dated pregnant Western mixed-breed ewes at 121-127 days gestation (term $=145 \mathrm{~d}$ ). Epidural anesthesia was induced with $4 \mathrm{~mL}$ of $1 \%$ tetracaine hydrochloride; intermittent boluses of ketamine ( $100 \mathrm{mg}$ ) were administered intravenously for sedation as required. A continuous infusion of $0.9 \% \mathrm{NaCl}$ was given to the ewe throughout surgery. Local anesthesia with $0.5 \%$ lidocaine hydrochloride was used for all incisions. Using this combination of ketamine and local anesthesia, fetuses do not respond to surgical incisions.

Polyvinyl catheters were inserted into the ewe's pedal vein and artery and advanced into the inferior vena cava and descending aorta for fluid administration and blood pressure monitoring. A hysterotomy was performed through a midabdominal incision and polyvinyl catheters similarly inserted into the fetal pedal vein and artery and advanced to the inferior vena cava and descending aorta. The fetal left chest was then identified and a 
left thoracotomy performed; the left lung was retracted to expose the great vessels and the ductus arteriosus. After the ductus was dissected from the surrounding tissue, $10 \%$ buffered formalin solution was injected into the vessel wall to destroy the muscular layer. A mechanical snare (made from a cardiac catheterization guide wire and a catheter sheath) was then looped around the ductus and brought through the fetal chest wall. A catheter was placed in the pulmonary artery. The fetal thoracotomy and the hysterotomy were closed, and the pregnancy allowed to continue $(4,5)$.

Two $d$ after the initial surgery, the ewe's abdominal incision was reopened under epidural anesthesia, and the fetus was delivered onto the maternal abdomen. The trachea was intubated with a 4.0 Fr cuffed endotracheal tube. Sheep surfactant, prepared from lung lavages of healthy adult sheep as previously described (16), was instilled into the trachea $(50 \mathrm{mg}$ lipid $/ \mathrm{kg}$ body wt); and the fetus was maneuvered from side to side to achieve even lung distribution. This treatment enables survival of premature lambs for several hours $(16,17)$. The umbilical cord was then ligated and the lamb delivered to a warming table where mechanical ventilation was initiated with a time-cycled, constant-flow infant ventilator (Sechrist, Anaheim, CA). Under local anesthesia, additional polyvinyl catheters were inserted into the right upper pedal and umbilical arteries and into the jugular vein and carotid artery; the latter two catheters were advanced into the superior vena cava and into the left ventricle, respectively.

The fetus was paralyzed with $0.4 \mathrm{mg}$ of pancuronium bromide during the period of mechanical ventilation and given diazepam $(0.3 \mathrm{mg} / \mathrm{kg}$ intravenously) for sedation. All intravascular catheters were kept patent during the experiment by infusion of small boluses of heparinized $5 \%$ dextrose in water $(<1 \mathrm{~mL} / \mathrm{kg} / \mathrm{h})$. The lambs were dried with a towel and covered with a plastic sheet to reduce evaporative heat loses. Rectal temperature was maintained at $38-39^{\circ} \mathrm{C}$ with an Aquamatic K-pad (American Hospital Supply, McGaw Park, IL) and with radiant heat lamps. Heparinized fetal or maternal blood was transfused to replace blood loss from sampling.

EXPERIMENTAL PROTOCOL. The experiment began when the umbilical cord was ligated. The ventilator settings were set at peak inspiratory pressure of $25-28 \mathrm{~cm} \mathrm{H}_{2} \mathrm{O}$, a positive endexpiratory pressure of $2.5-3.0 \mathrm{~cm} \mathrm{H}_{2} \mathrm{O}$, inspiratory time of 0.6 $\mathrm{s}$, respiratory rate of $40-50$ breaths $/ \mathrm{min}$, and fractional inspired $\mathrm{O}_{2}$ of 1.0. Settings were maintained within these narrow limits so that any observed differences in lung protein leakage or water accumulation would not be attributed to differences in mode of ventilation.

The lambs were randomly assigned to one of two groups: in group I the ductus remained open throughout the experiment (open-ductus group); in group 2 the ductus was mechanically closed by tightening the snare $1 \mathrm{~h}$ after delivery (closed-ductus group). In all other respects the two groups underwent the same experimental protocol as described below.

The rate at which albumin left the intravascular space and entered the lung and airways was determined during the third hour after delivery. At $2 \mathrm{~h}$ after delivery a blood sample was drawn for assay of plasma albumin concentration, and $10 \mu \mathrm{Ci}$ of ${ }^{125} \mathrm{I}$-albumin (Mallinckrodt, St. Louis, MO) mixed in $10 \mathrm{~mL}$ $0.9 \% \mathrm{NaCl}$ was injected into the inferior vena cava. At 15 -min intervals thereafter, blood samples were drawn for assay of ${ }^{125} \mathrm{I}$ activity. Left ventricular output, pulmonary blood flow, and flow through the ductus arteriosus were determined at $2 \frac{1 / 2}{h}$ of age. Two different radiolabeled microspheres $\left({ }^{85} \mathrm{Sr}\right.$ and ${ }^{65} \mathrm{Zn}$ ) were injected into the left ventricle and the inferior vena cava while reference blood samples were continuously withdrawn from the ascending and descending aorta (18). Throughout the experiment, arterial $\mathrm{pH}, \mathrm{PaCO}_{2}$, and $\mathrm{PaO}_{2}$ were measured every $30 \mathrm{~min}$ using a Corning blood gas analyzer (Corning Medical and Scientific, Medfield, MA). Vascular and left ventricular pressures were measured continuously with a Sensormedic Dynograph
R611 multichannel recorder and Beckman pressure transducers (Sensormedic, Anaheim, CA). Signals were averaged electronically to obtain mean pressures.

Three $h$ after delivery, the lambs were given $2000 \mathrm{U}$ of heparin, blood was drawn for hemoglobin and ${ }^{125} 1$ measurements, and the lambs were killed with $50 \mathrm{mg} / \mathrm{kg}$ of pentobarbital. Immediately after death, the chest was opened, the trachea clamped, and the lungs extracted.

PROCESSING OF LUNGS. After extraction of the lungs, the two major bronchi were clamped and the two lungs separated and weighed. The left lung was used to determine the extravascular water content of the lungs and the right lung was used to determine the rate at which albumin entered the lung tissue and airspaces from the vasculature.

Left Lung. The left lung was homogenized in a Waring Blendor (Waring Products Dir., New Hartford, CT) and a measured aliquot was taken to determine the ratio of lung wet wt to lung dry wt; this measurement was used to assess the extravascular water content of the blood-free lung $(19,20)$. The remainder of the lung was used for microsphere measurements of pulmonary blood flow.

Right Lung. Lung lavage. The right lung was lavaged with four separate passes of $0.9 \% \mathrm{NaCl}$ at $4^{\circ} \mathrm{C}$, each pass being carried out at a constant pressure head of $15 \mathrm{~cm} \mathrm{H}_{2} \mathrm{O}$. The rationale for this method of lavage was established in preliminary experiments in which ${ }^{125}$ I-albumin was given immediately prior to killing the lamb. The right lung was then extracted and a lavage, as described above, was carried out at constant pressure heads of 10,15 , and $20 \mathrm{~cm} \mathrm{H}_{2} \mathrm{O}$. At 10 and $15 \mathrm{~cm} \mathrm{H}_{2} \mathrm{O}$ pressure heads, the lavage fluid radioactivity was within the range of background radiation. Lavage performed at $20 \mathrm{~cm} \mathrm{H}_{2} \mathrm{O}$ pressure head produced fluid containing $0.2 \%$ of the injectate counts, well above background radiation. At $15 \mathrm{~cm} \mathrm{H}_{2} \mathrm{O}$ pressure head, the lungs appeared maximally distended with lavage fluid. Thus, lavage at $15 \mathrm{~cm}$ $\mathrm{H}_{2} \mathrm{O}$ pressure head appeared to provide sufficient distending pressure without itself inducing lung tissue disruption that could cause spillover of intravascular radioactivity into the alveolar wash.

The amount of lavage fluid given and recovered was recorded. Aliquots of the lavage, in triplicate, were assayed for albumin concentration and ${ }^{125}$ I activity. Thus, the total amount of albumin and ${ }^{125}$ I obtained by lavage could be calculated. Aliquots of lavage were also measured for ${ }^{125} I$ activity after precipitation with $10 \%$ trichloroacetic acid. This was done to ascertain that the tracer was bound to the albumin. In two animals more than $20 \%$ of the ${ }^{125}$ I was not precipitable; results from these two (one with an open ductus and one with a closed ductus) were not included in the analysis of ${ }^{125} \mathrm{I}$ measurements. In all other cases the ${ }^{125} \mathrm{I}$ tracer was over $95 \%$ protein-bound in both the lavage $(96.6 \pm$ $1.5 \%)$ and the injectate $(98.0 \pm 0.7 \%)$.

Right lung homogenate. After lavage, the right lung was homogenized and aliquots taken for assay of ${ }^{125}$ I activity. When measuring ${ }^{125}$ I activity in lung homogenate, a small percentage of the radioactivity in the ${ }^{125} \mathrm{I}$ window was due to the ${ }^{85} \mathrm{Sr}$ - and ${ }^{65} \mathrm{Zn}$-tagged microsphere also present. To eliminate the contribution of measured activity in the ${ }^{125} \mathrm{I}$ range due to the microspheres, we measured the spill-over of activity from different concentrations of ${ }^{85} \mathrm{Sr}$ - and ${ }^{65} \mathrm{Zn}$-labeled microspheres to create a matrix of interference coefficients, allowing calculations of counts in the ${ }^{125}$ I region originating from the microspheres. These were subtracted from the measured activity in the ${ }^{125} I$ window to give the net ${ }^{125} I$ counts used in our calculations.

An aliquot of the right lung homogenate was centrifuged at $8000 \times g$ for $30 \mathrm{~min}$ and the supernatant assayed for $\mathrm{Hb}$ content. $\mathrm{Hb}$ content and ${ }^{125} \mathrm{I}$ radioactivity were also measured in a sample of aortic blood taken just before death. The contribution of intravascular blood associated with the homogenate was estimated from the $\mathrm{Hb}$ content and ${ }^{125} \mathrm{I}$ activity of the blood and the total homogenate volume, with the assumption that all the $\mathrm{Hb}$ associated with the lung homogenate was intravascular in 